

\begin{abstract}
Mismanaging the pursuit of happiness causes negative psychological effects such as stress and disappointment. The resultant stress often manifests itself as psychological and physical health problems. We explore the problems of measuring happiness according to materialistic wealth and demonstrate that misinterpreting happiness can lead to a stress inducing pursuit. The happiness that human beings pursue is often material-based hedonism whereas eudaimonic happiness has been shown to be a by-product of the pursuit of meaningful activities. Pursuing a predefined happiness, the failure to achieve it and the resistance to it can create stress induced psychosomatic health problems; temporomandibular disorders (TMD) are one such example. Masticatory myofascial pain syndrome is a form of TMD that has a strong association to psychological stress. In this paper the research on TMD associated facial pain across different socioeconomic status (SES) groups is utilized to compare an objective, stress related physiological disorder with happiness data. We also discuss how the pressures of pursuing socially determined aesthetic happiness such as conforming to society's expectations of smile and facial aesthetics can drive people to make surgical or orthodontic changes. This review proposes that pursuing happiness has the propensity to cause not only psychological stress but also negative behaviors. We aim to encourage further scientific research that will help to clarify this philosophical pursuit.
\end{abstract}

Keywords: happiness; stress; socioeconomic status (SES) groups; temporomandibular disorders (TMD); dental aesthetics 


\title{
The Pursuit of Happiness, Stress and Temporomandibular Disorders
}

\author{
D. Marcus \& E. Baehrisch
}

\section{Introduction}

In this research, we attempt to add a counterintuitive point of view to the existing idea that the pursuit of happiness leads to happiness and suggest instead that the pursuit of happiness can lead to stress. Throughout our study, we problematize modern human beings' pursuit of hedonic satisfaction and investigate the consequences of misinterpreting the concept and mismanaging the pursuit of happiness. Levels of happiness and stress vary according to socioeconomic status (SES) with mixed and sometimes unclear results. Research on temporomandibular disorders (TMD), particularly stress related to the myofascial pain syndrome form of TMD, is used in a novel way as an epidemiological tool to compare with current happiness data. Both TMD and happiness are draped in the biopsychosocial fabric of human life, juxtaposing the two is an interesting way to utilize an objective stress related disorder to help demystify a subjective concept. We hope to encourage further research that will clarify the concept of happiness and investigate the psychological effects of pursuing it.

\section{The Misinterpretation of Happiness}

\section{Misunderstanding the concept of pursuing happiness}

Modern human beings tend to think that happiness can be pursued like money. Myers and Diener (1995) have succinctly described how people today think about happiness and money: "Few agree that money can buy happiness, but many agree that a little money would make them a little happier" (Myers \& Diener, 1995, p. 13). The assumption that financial and materialistic success paves the road to happiness drives modern human beings to pursue hedonism, focusing on material values. The preference for a materially affluent life does not come without an opportunity cost. Since time, effort, and labor are spent to achieve a pre-set lifestyle defined by hedonism, visceral happiness or subjective well-being is ironically often sacrificed in the course of pursuing happiness. In a capitalist setting, people are accustomed to speculation about what they might gain from their activities, however consideration towards what they might lose may be of greater overall benefit.

\section{The elements of happiness}

In times of antiquity, Aristotle urged people to actively pursue happiness (Aristotle \& Jackson, 1973). However, what Aristotle meant by activity was the activity of a free person - even above political activity - this may have included music, literature, philosophy, contemplation and meaningful social gatherings, and not a slave's busyness (Fromm, 2009, p. 75). In today's world people seem to do just the opposite; they actively engage in what Aristotle would call a slave's busyness and neglect a free man's pursuits.

We believe that Maslow's hierarchy of needs (Maslow, 1943) has suitably addressed various elements of happiness. The hierarchy from bottom to top consists of needs titled: physiological, safety, love/belonging, esteem and self-actualization (Maslow, 1943, p. 18). Although the order and ranking of Maslow's hierarchy of needs remain 
the subject of discussion, the constituent needs mentioned are an important contribution to the composition of happiness. What we would like to point out is that the five aforementioned needs are said to be necessary in order to attain a happy state, modern human beings, however, restrict their exposure to Maslow's elements of needs due to a predilection towards money. Money secures physiological needs and safety, possibly esteem and self-actualization but not necessarily love and belonging. Work is often considered to be an important aspect of modern life, however, for many people, work has been degenerated into an activity to earn money or enhance esteem, rather than a way to self-actualize.

In happiness research, various disciplines have emphasized narrow measurements of happiness from their own fields of expertise such as economics or psychology, however happiness research is gradually becoming more multifarious. The recent trend of happiness research to diversify the determinants of happiness - e.g. friendship, political freedom, perceptions of corruption, and freedom to make life choices — is very positive. Happiness research in a larger scale such as the World Happiness Report (Helliwell, Layard, \& Sachs, 2013) conducted by the United Nations Sustainable Development Solutions Network (UNSDSN) or Happy Planet Index (New Economics Foundation, 2012) includes not only pecuniary values but also health, human relationship, inner resources, belonging to a wider community and even ecological footprints. In saying this, however, the research on happiness is still immature and further development is needed to enhance our understanding.

\section{Hedonic adaptation and relative income}

Richard A. Easterlin found, when comparing countries with sufficient income to meet people's basic needs, the average reported level of happiness did not differ much according to national income per person (Easterlin, 1974, pp. 118-119). This phenomenon that happiness and wealth do not go up together after basic needs are satisfied is called the Easterlin Paradox. Easterlin questioned why a high income did not guarantee happiness, and found the answer in adaptation (Easterlin, 2003, p. 11180). According to the theory of adaptation, when one's income gets higher, one's happiness level goes up temporarily until one adapts to his new income level. Then, the happiness level drops and reverts back to the previous level (Clark, Frijters, \& Shields, 2008, p. 105; Easterlin, 2003).

Brickman, Coates and Janoff-Bulman (1978) showed, in their research, that lottery winners' life satisfaction was not higher than the control group due to the winners' adaptation and subsequent aspirations (Brickman, Coates, \& Janoff-Bulman, 1978; Clark et al., 2008, p. 109). The lottery winners desired different levels of pleasure and got used to a higher standard of living, therefore, the overall level of happiness even after a very positive cash shock did not increase (Clark et al., 2008, p. 109). Inglehart and Rabier (1986) determined that when a change in financial situation happened in the previous twelve months, the income change was positively correlated to happiness, because the subjects had not yet adapted to the new income. This research supports the claim that the level of current income is not strongly related to happiness (Clark et al., 2008, p. 109; Inglehart \& Rabier, 1986).

Another characteristic of adaptation, which interferes with people's happiness in the material context, is the fact that people adapt more to rises in income rather than falls (Burchardt, 2005; Clark et al., 2008, p. 109). Therefore, the presence of more income is hardly felt whereas the loss of money is easily perceived. In addition, Easterlin discovered that although there might be complete hedonic adaptation with income, this does not mean that there is complete adaptation with regard to all sources of happiness (Easterlin, 2003, p. 11180). In his research (2003), he emphasized that adaptation does not work in human relationships, at least in marital life. It was demonstrated that $65 \%$ of men, aged 18 and over, who never married, wanted a happy marriage rather than adapting to their single life (Easterlin, 2003, p. 11181).

Along with the theory of adaptation, the relativity of income is noteworthy. Solnick and Hemenway's survey clearly showed that people perceive money as a relative rather than an absolute value (Solnick \& Hemenway, 
1998). In their survey, respondents were asked to choose between A (Your current yearly income is $\$ 50,000$; others earn $\$ 25,000$ ) and B (Your current yearly income is $\$ 100,000$; others earn $\$ 200,000$ ). The respondents preferred A to B. Similarly, Zizzo and Oswald found that people would give up money if this action caused others to give up a slightly larger amount of money (Zizzo \& Oswald, 1999). The relativity of income makes it harder for people to feel happiness from the money they earn, reinforcing the notion that money is not a reliable variable of happiness.

\section{Different SES groups and happiness}

Numerous research findings have shown that, above a certain level of income, possibly subsistence income, money does not make much of a difference to happiness (Easterlin, 1974; Freedman, 1978). While the exact figure for the subsistence level income varies depending on the national and individual circumstances, some researchers report that it could be as low as US \$10,000 per annum (Clark et al., 2008, p. 96; Frey \& Stutzer, 2002; McMahon, 2006).

As for the correlation between different SES groups and happiness the literature yields mixed and often controversial results. After basic needs are met, interestingly, higher SES groups exhibited a relatively small positive difference in happiness levels compared to lower SES groups where a larger difference might be expected (Lykken $\&$ Tellegen, 1996, p. 187).

Notably, people in different SES groups have varying levels of expectations and aspirations. Lower SES individuals have been shown to have less pressure - internal and external - to achieve economic success, whereas those in higher SES groups often need to manage very high expectations for educational and economic success (Andres, Adamuti-Trache, Yoon, Pidgeon, \& Thomsen, 2007). In addition, Baum, Garofalo and Yali (1999) report that anxiety/somatization, loss of weight, impairment at work, somatic anxiety, and hypochondriasis are more easily found in lower SES groups, while feelings of guilt, depersonalization and obsessional/compulsive symptoms, and cognitive disturbance are more commonly observed in higher SES groups (Baum, Garofalo, \& Yali, 1999, p. 139).

More radically, Lykken and Tellegen (1996), in their subjective well-being (SWB) measurement on several thousand middle-aged twins in Minnesota, highlighted that SES, educational attainment, family income, marital status, and religious commitment do not significantly affect individuals' well-being. In their research, all above mentioned factors showed less than 3\% variance in well-being (Lykken \& Tellegen, 1996, p. 186). Although their statement that many happiness variables - except genetic variation - are all trivial needs to be further examined, their claim that different SES groups do not display much difference in SWB levels is worth noting since it further strengthens the idea that money and status do not buy happiness.

\section{Mismanagement of the Pursuit of Happiness}

\section{Unhappiness caused by the pursuit of happiness}

Mauss, Tamir, Anderson and Savino's research (2011) found out that people who value happiness highly are more likely to be disappointed with how they feel. Ironically their desire for happiness appears to lead to unhappiness (Mauss, Tamir, Anderson, \& Savino, 2011, p. 807). When the emotional goal and the underlying emotional feeling are incongruous, disappointment is the inevitable result. Simply wanting to be happy or becoming aware of happiness can diminish happiness (Deci, Koestner, \& Ryan, 1999; Mauss et al., 2011, p. 813; Schooler, Ariely, \& Loewenstein, 2003; Schooler \& Mauss, 2010; Wegner, 1994).

More research has been conducted to prove that expectation causes disappointment. Schooler, Ariely and Loewenstein (2003) studied how much money 475 people spent on the celebration of New Year's Eve in 1999 and inferred that those who had higher expectations and spent more money on the event were ultimately more 
disappointed (Schooler et al., 2003, pp. 60-61). Similarly, Geers and Lassiter's experiment (1999) proved that those who expected a film to be enjoyable experienced significantly less enjoyment than people who had no expectation (Geers \& Lassiter, 1999). These research findings imply that misaligned expectations and monitoring happiness can in fact impair and detract from the experience.

\section{Misallocation of time and weakened social connections}

There have been observations, which demonstrate that once an individual has achieved a certain financial level, the main causes of increased happiness is not income but friends and family (Lane, 2000). To their detriment, people tend to value the material rather than activities with friends and family. Robert H. Frank (1997) questioned which was a wiser choice between "having a 5000-square-foot house and meeting friends one evening each month" and "having a 3000-square-foot house and meeting friends four evenings a month" (Frank, 1997, p. 1838). A sensible choice to increase the level of happiness would be the latter, but people opted for the bigger house rather than spending time with friends.

Social connections such as family, friends, neighbors and community involvement affect health as well as happiness. Research shows that there are strong correlations between social connections and health (Berkman \& Syme, 1979; J. F. Helliwell \& Putnam, 2004). In a similar context, individuals who report living in a high-trust environment also acknowledge significantly higher levels of life satisfaction and of happiness (J. F. Helliwell \& Putnam, 2004, p. 1442).

Although many economists correlate income and happiness, the amount of happiness generated by a higher income is not much. According to Bruno S. Frey's research, provided that "not too happy" is 1, "pretty happy" is 2, and "very happy" is 3, doubling income was reported to increase happiness on average by a 0.05 score point for those with lower income, and by a 0.03 score point for those with higher income (Frey, 2008, pp. 28-29). Considering that doubling income only adds 0.03-0.05 happiness score points, those who rush towards money and career success might benefit from determining whether or not they are allocating their time wisely. The highly career driven are more likely to sacrifice other important elements of happiness, such as time for exercise, family and friends, self-development and leisure in order to increase income. Often non-pecuniary values such as health (Fontane, 1996; Palmer, 1995; Plante \& Rodin, 1990) or social networks (Argyle, 1997) are shown in several studies to be stronger positive correlates of psychological well-being than money.

\section{Happiness and health problems: hedonic happiness vs. eudaimonic happiness}

Philosophies such as Aristotle's eudaimonia, Thomas Aquinas's vita contemplativa and Karl Marx's alienation commonly highlight that an important component of happiness is quality of life rather than productivity and material values (Fromm, 2009, pp. 75-78). Likewise, modern physiological and psychological research also takes note of the two different types of happiness: circumstance-based hedonic happiness and activity-based eudaimonic happiness. Hedonic happiness is the sum of an individual's affective experiences and eudaimonic happiness is a result of striving toward meaning and a noble purpose beyond simple self-gratification (Fredrickson et al., 2013, p. 13684; Friedman, 2012; Ryan \& Deci, 2001; Ryff \& Singer, 1996; Ryff, Singer, \& Love, 2004; Waterman, 1993).

There is a stark contrast between hedonic happiness and eudaimonic happiness in terms of adaptation. Sheldon \& Lyubomirsky (2006) found that happiness created by intentional activity changes, such as exercise, education and pursuing meaningful goals, is much more resistant to adaptation than happiness generated by a superficial circumstantial change, such as income, car ownership or a house (Sheldon \& Lyubomirsky, 2006, p. 55). Positive effects of education on happiness also confirm the importance of eudaimonic happiness. Easterlin found that those with more education are happier than those with less (Easterlin, 2003, p. 11180) and Frey adduced data 
collected in Germany and concluded that people with more years of education show higher satisfaction scores than those with fewer years of education (Frey, 2008, p. 36).

There is also a difference between hedonic happiness and eudaimonic happiness from a biopsychosocial point of view. Immune cells show a systemic shift in gene-expression under chronic stress, threat or uncertainty, and this shift is called conserved transcriptional response to adversity (CTRA) (Fredrickson et al., 2013, p. 13684). According to Fredrickson et al (2013), people with high levels of hedonic well-being showed up-regulation of stressrelated CTRA, and people with high levels of eudaimonic well-being were associated with CTRA down-regulation (Fredrickson et al., 2013, p. 13684). Their research also found that hedonic well-being was involved in an increased expression of proinflammatory genes and decreased expression of genes involved in antibody synthesis (Fredrickson et al., 2013, p. 13684). Considering that chronic CTRA activation may promote inflammation-mediated cardiovascular, neurodegenerative, and neoplastic diseases and impair host resistance to viral infections (Cole, 2012; Finch, 2007; Fredrickson et al., 2013, p. 13684; Irwin \& Cole, 2011), we arrive at a conclusion that pursuing hedonic happiness is neither long lasting due to adaptation nor healthy.

\section{Temporomandibular Disorders (TMD) - A Window to the Mind}

TMD has been defined as a collective term for a group of disorders that can present themselves as clinical problems in the masticatory musculature and/or the temporomandibular joint (McNeill, Mohl, Rugh, \& Tanaka, 1990, as cited in Mercuri, 2013, p. 112). TMDs have been recognized as a group of biopsychosocial illnesses influenced by physical, psychological and psychosocial factors (Suvinen, Reade, Kemppainen, Könönen, \& Dworkin, 2005, p. 615). The strong relationship that TMD — particularly the subtype myofascial pain syndrome has with stress provides a useful angle to view psychological stress endured by populations in different socioeconomic status (SES) groups. It has been acknowledged that the link between SES and TMD is not well understood (Benoliel et al., 2011; Plesh, Crawford, \& Gansky, 2002), and this uncertainty is an invitation to explore the complex relationship between SES, stress and happiness. We do not intend to present a correlation between TMD and pursuing happiness. Rather, by comparing data on happiness and TMD - both broadly relevant topics with psychosocial implications — shared counterintuitive patterns arise within different SES groups. These unexpected epidemiological data, such as an increase in stress related TMD facial pain with wealth, may help us to better understand how the pursuit of happiness can lead to the development of psychological stress.

\section{TMD and stress, stress and TMD}

The range of temporomandibular disorders is wide and has been subject to many systems of classification, one of which is the well known RDC/TMD (Research diagnostic criteria for temporomandibular disorders) by Dworkin and LeResche (Dworkin \& LeResche, 1992). In the RDC/TMD, three groups of TMD are classified as myofascial pain disorder (Group I), disc displacement disorder (Group II) and degenerative disease disorder (Group III). In an overview of TMD, Durham (2008) listed some signs and symptoms of TMD, which included joint noises, jaw locking open or closed, pain (in the head, neck and shoulders), muscular tenderness (in the face, neck and shoulders), ear complaints (otalgia, tinnitus) and psychosocial effects. He also noted "psychological disorders are prevalent in patients suffering from TMD” (Durham, 2008, p. 61).

A detailed overview of TMD classification and aetiology is beyond the scope of this research. We will focus on the aspects of TMD most relevant to psychological stress, namely, myofascial pain syndrome and bruxism (clenching and grinding).

Current evidence concerning the origins of orofacial pain as outlined in the review by Benoliel et al. (2011) supports the multifactorial theory proposed by Okeson (1996) and the biopsychosocial concept by Dworkin and 
Burgess (1987) (as cited in Benoliel et al., 2011, p. 25). When analyzing the cause of persistent orofacial pain, the multifactorial and biopsychosocial theories suggest that a complicated interaction of environmental, emotional, behavioral and physical factors should be taken into account. It is for this reason that TMDs and their symptoms are highly individualized and variable. Benoliel et al.'s detailed review (2011) addressed many possible pathophysiological factors of persistent orofacial muscle pain and they endowed good evidence levels to endogenous pain modulation, stress, depression, sleep disorders and childhood events. The psychological and psychosocial components of TMD associated orofacial pain are constantly reinforced, however these factors are presented sometimes as propagating and sometimes as causal. For example, stress related disorders are painted as "perpetuating rather than initiating factors" (Benoliel et al., 2011, p. 29) only to be followed by a claim that muscle hypoperfusion caused by stress-related daytime clenching and sympathetic nervous system modulated myofascial pain syndrome may be "the primary factor in initiating muscle pain" (Benoliel et al., 2011, p. 32). These apparent contradictions are regularly managed by emphasizing a lack of evidence to be sure one way or the other. An attempt at clarity is anchored in the aforementioned theory of a complex interaction of multiple factors, which supposes that, depending on the individual, any combination of the vast list of aetiological factors may result in persistent orofacial muscle pain (Benoliel et al., 2011, p. 34).

As we have discussed, the significance of biopsychosocial factors as a causal and/or propagating element in TMD is widely recognized. Stress has well documented physiological correlates such as the activity of the adrenal glands described as part of the fight or flight response by Cannon (Cannon, 1914). This was further defined by Selye (Selye, 1975, p. 39) and he termed the agreeable/beneficial and healthy response to a demand for adaptation as eustress and a disagreeable or pathogenic response as distress. Selye (Selye, 1976, p. 54) proposed that the release of stress hormones along the Hypothalmic-Pituitary-Adrenal axis (HPA axis) such as ACTH, glucocorticoids, and catecholamines - which have been implicated in immunosuppression, cardiovascular disease and psychological disorders (Radley, 2012) - occurs in both eustress and distress. The concept of eustress, where the positive interpretation of a stressor results in more favorable psychological and physiological outcomes, in spite of the production of stress hormones has received significant scientific reinforcement (Jamieson, Mendes, \& Nock, 2013). Furthermore, the effects of emotional stress on the HPA axis have been explained by the modulation of HPA axis activity by the emotional centre of the brain, the limbic system (Radley, 2012). An individual's perspectives and cognitive appraisal abilities appear to play a critical role in determining how stress affects health.

In addition to the physiological effects of stress, there are also psychological symptoms. These have been outlined by Derogatis and Unger (Derogatis \& Unger, 2010, p. 1743) in the "Symptom Checklist-90-Revised," or SCL-90-R. The SCL-90-R has been widely used in research to measure the psychological symptoms of psychological distress. The symptom list includes somatization, obsessive-compulsive, interpersonal sensitivity, depression, anxiety, hostility, phobic anxiety, paranoid ideation, and psychoticism. Many of these psychological symptoms have been researched individually and have their own related health outcomes; as a limited example, depression is associated with bruxism, chronic widespread pain and TMD associated persistent orofacial muscle pain (Benoliel et al., 2011; Durham, 2008; Gungormus \& Erciyas, 2009; Velly et al., 2010). The literature does not support a correlation between bruxism and all forms of TMD (Benoliel et al., 2011; Durham, 2008; Velly et al., 2010), however daytime clenching in particular has been shown to be associated with psychological stress and jaw muscle pain (Bayar, Tutuncu, \& Acikel, 2012; Manfredini \& Lobbezoo, 2009).

Parafunctional behavior such as bruxism affects and activates the head and neck muscles. Myofascial pain syndrome - which is the underlying condition in persistent masticatory muscle pain - has been defined as pain of muscular origin where the painful site has a taut band of muscle with a zone of tenderness in it known as a trigger point (Simons, Travell, \& Simons, 1999, as cited in Gerwin, 2001, p. 412). A buildup of the neurotransmitter 
acetylcholine at the neuromuscular junction is said to be a potential cause for the dysfunctional trigger points in skeletal muscle tissue found in myofascial pain syndrome (Gerwin, 2001, p. 417). The process involving increased muscle contractility and decreased intramuscular blood perfusion leading to muscle pain and referred pain has been widely reviewed and supported (Passatore \& Roatta, 2007).

A more direct explanation that connects psychological stress and masticatory muscle pain has been described by Hidaka, Yanagi and Takada (Hidaka, Yanagi, \& Takada, 2004a, 2004b), where it is emphasized that intramuscular blood flow is critical for the metabolic control of humoral agents. Their research revealed how psychological stress resulting in the activation of the sympathetic nervous system (SNS) can alter the muscle tone and the intramuscular blood circulation in a major muscle of mastication (the masseter muscle). This demonstrates how psychological stress can cause muscular pain syndromes. The direct actions of psychological stress on muscles and muscle pain may be useful as an objective measurement to penetrate the subjective causes of psychological stress, however further research is required to determine if this is so.

A better understanding of subjective perspectives on life and happiness is necessary. The influence of psychological stress on the mind and body is profound and people respond to the vast array of life's stressors in varying ways and with different coping mechanisms. When the stressor is experienced as distress, according to the Selye's definition, individuals can face undesirable and/or pathological outcomes (Selye, 1975). There is a long list of syndromes, diseases and other health problems associated with stress. Due to its strong correlation with psychological stress, the myofascial pain syndrome form of TMD appears to serve as a clean window to look through in order to observe people's stress experience. Low SES has often been associated with chronic stress and distress (Baum et al., 1999, p. 131). When analyzing TMD associated orofacial pain and population happiness, our research suggests, against logical expectations, that lower SES groups (who can meet basic needs) experience less TMD and exhibit only a small difference in happiness compared to higher SES groups. TMD is not reserved for the working class just like happiness does not belong solely to the upper class. Stress caused by mismanaging the pursuit of happiness for instance, is subject to individual interpretation. How do those with a less fortunate lot avoid orofacial pain from TMD and maintain comparable levels of happiness with the more fortunate? Why do some of the more privileged suffer from increased TMD facial pain and underwhelming happiness levels? These are some of the questions that can be more effectively tackled with a deeper knowledge and understanding of happiness.

\section{Stress induced TMD in different SES groups}

TMD is the most common cause of chronic orofacial pain (Benoliel et al., 2011, p. 24) and as discussed earlier, chronic orofacial pain is correlated to psychological stress. The relationship of TMD to SES however, is not clear in the literature. This unclear connection may be attributed to a paucity of large scale randomized controlled trials and peer reviews; the difficulty of consistently and accurately diagnosing TMD due to multiple classification systems and diagnostic criteria; variable levels of people reporting symptoms of TMD; and the inherent cyclical nature of TMD whose symptoms tend to come and go over time. In spite of these challenges there are numerous studies that demonstrate variation in the incidence of TMD at the SES and cultural levels (Komiyama et al., 2009; LeResche, Manci, Drangsholt, Huang, \& Von Korff, 2007; Plesh et al., 2002).

Plesh et al. (2002) found that when comparing American women of higher SES to American women of a lower SES, the higher SES group reported more morning headaches and bruxism and had double the prevalence of TMD related facial (Plesh et al., 2002, p. 518). The study concluded that "face/jaw pain prevalence increases with household income and possibly parental education, demonstrating the strong role SES plays in facial pain selfreports" (Plesh et al., 2002, p. 521).

As to what causes the varied incidence of TMD across SES groups, especially when the incidence has been shown to increase with SES, the study by LeResche et al. (2007) may lend some insight. The development of TMD 
associated facial pain in asymptomatic 11 year old subjects by the age of 14 was predicted by certain psychological and physical symptoms that included somatization, the number of existing pain conditions and reporting "being neutral about or dissatisfied with life at age 11" (LeResche et al., 2007, p. 275). The findings from LeResche et al.'s study reflected the counterintuitive correlation of low SES with less TMD associated facial pain and vice versa, the reason for which was acknowledged as being unclear (LeResche et al., 2007, p. 276). In addition to this, the psychological contribution of the dissatisfaction with life to TMD related facial pain is notable.

A demographic aged 11-14 years from America is not likely to have experienced occupational, independent financial or chronic health problem related stress. Certain SES and cultural related factors such as familial/social expectations and the interpretation of social pressures are influential in the development of an individual's psychological state (Andres et al., 2007; Diemer \& Hsieh, 2008; Galati, Manzano, \& Sotgiu, 2006; Lu, Gilmour, \& Kao, 2001; Steele \& Lynch, 2012; Tkach \& Lyubomirsky, 2006; Uchida, Norasakkunkit, \& Kitayama, 2004). The ubiquitous concept of the pursuit of happiness is a broad and vague task familiar to populations from all walks of life. As discussed earlier in this paper, if it is misinterpreted or the pursuit itself is mismanaged, an individual's stress levels and happiness can be negatively impacted. Social environments and expectations vary between SES groups and cultures, as do coping mechanisms for dealing with life's stressors. The final chapter of this paper will explore an example of the pursuit of happiness leading to stress by investigating how the pressure from predefined societal aesthetic ideals can drive people to surgically change their appearance or mechanically straighten their teeth. When the pursuit of happiness is experienced as distress rather than eustress, undesirable stress related symptoms such as TMD associated facial pain (to which no SES group is immune) or aberrant behavior may ensue.

\section{Responses to the Pressure to Pursue Aesthetic Happiness}

The facial feedback theory has been formed over decades but its beginnings may be originally traced back to Darwin in 1872 (Darwin, 1965). The theory suggests that even during a manipulated positive facial expression the emotions of the individual are positively affected. The physical expression of a smile can have beneficial psychological effects such as reducing stress whereas an unhappy countenance may in itself evoke a negative psychological state (Alam, Barrett, Hodapp, \& Arndt, 2008; Davis, Senghas, \& Ochsner, 2009; Kraft \& Pressman, 2012). The importance of a smile however goes beyond its inherent emotional effects. Society places a great deal of emphasis on smile and facial aesthetics. For those who do not have the appearance that society demands, a psychosocial struggle may ensue. This chapter will show how the pressure from pursuing these predefined aesthetic ideals can drive people to seek surgery or orthodontic treatment as a way of managing both their stress and subjective concerns with their appearance.

\section{Social aesthetic pressure: predefined happiness}

If people grow up pursuing the social definitions of aesthetic happiness but cannot attain them — in reality or in their own mind - they may suffer from psychological stress (Jung, Lennon, \& Rudd, 2001, p. 171). In an effort to avoid or eliminate this stress people may select a surgical solution (Bradbury, 1994; Kinnunen, 2010, p. 268). Cosmetic surgery is seen by some as being a way to defy the aging process and counteract the unhappiness that is felt as a result of looking older (Kinnunen, 2010, p. 258). Surgery has also been found to be utilized in order to avoid other social stigmas such as small breast size, oddly shaped noses, and being overweight. Furthermore, some turn to surgery in order to distance themselves from their cultural or racial background (Bradbury, 1994, pp. 303-304).

Societal pressures, expectations and definitions directed at what appearance is necessary to be happy are 
influential factors in people's desire to alter their appearance. Kinnunen (2010) in a study of Finnish cosmetic surgery patients observed that "women are socially defined and pressured to be concerned about their appearance" (Kinnunen, 2010, p. 259) and also remarked how surgery is used (among the Finnish subjects) to create whiteAmerican features that reflect positivity and happiness (Kinnunen, 2010, p. 269). Analyzing body image, Jung, Lennon, and Nancy (2001) reaffirmed the influence of societal pressures, saying, "women in many cultures, and particularly in western cultures, are socialized to be interested in beauty and fashion" (Jung et al., 2001, p. 171). However, social aesthetic pressures are not limited to women. Men and children are also subjected to predefined aesthetic ideals. Children learn that the bad guys in movies have ugly faces and crooked teeth. Television and magazines link good looks and straight teeth with inherent goodness, popularity and sociability (Klages \& Zentner, 2007, p. 105).

\section{Dental and facial aesthetic pressures}

The concerns people have about jaw size, profile appearance and tooth alignment have been shown to be mostly aesthetic (Pabari, Moles, \& Cunningham, 2011, p. 269). These aesthetic expectations can vary with culture, for example some African cultures find a gap between the two front teeth to be an attractive physical attribute (Feng, Newton, \& Robinson, 2001, p. 285). Social pressures play an integral role in the development of subjective aesthetic concerns. From a young age children experience teasing and social exclusion as a consequence of having a dental malocclusion. Studies have revealed that children with malocclusions such as crooked front teeth are viewed more negatively by their peers in athletics, social and health status, leadership and academic skills, honesty, intelligence, and personal happiness (Pithon et al., 2013; Verdecchia, Bee, Lombardo, Sgarbanti, \& Gracco, 2011).

The negative psychosocial implications of living with a societally defined poor smile or facial appearance are widely accepted and persist into adult life (Feng et al., 2001, p. 285; Johnston, Hunt, Burden, Stevenson, \& Hepper, 2010; Pabari et al., 2011). Some corollaries of negative psychosocial conditioning such as stress, selfesteem issues, social exclusion and teasing prove to be sources of motivation for adults and children alike to seek orthodontic and orthognathic treatment. In the study by Pabari, Moles and Cunningham (Pabari et al., 2011, p. 264), it was shown that motivation for adults when seeking orthodontic treatment was either internal and dependent on their own perceived need to correct a problem or external, influenced by family, friends or partners. In an analysis on orthodontic patient motivation, Prabakaran, Seymour, Moles, \& Cunningham (2012) found that children (who were also shown to have their own aesthetic concerns) were often guided by a parental decision (Prabakaran, Seymour, Moles, \& Cunningham, 2012). Interestingly, parental motivation for sending their children to have orthodontic treatment was rooted in wanting the best for their children and preventing future problems. Looking good and feeling happy are desires shared by both children and adults. Societal pressures propel people towards reaching or helping others reach these prescribed desires with psychological stress being both the by-product and the source of motivation.

The concept of pursuing happiness invades most aspects of life. In the realm of facial aesthetics immense pressure from society is felt from a young age. People who pursue this predefined aesthetic happiness respond to the pressure by making active changes to their face, teeth and jaws through non-surgical, surgical and orthodontic pathways. Before elective aesthetic surgery, patients are screened for psychological instability to ensure an optimal outcome. Orthodontics and orthognathic surgery are strongly linked to psychosocial benefits; they reduce stress and improve self-esteem (Johnston et al., 2010; Pabari et al., 2011; Pithon et al., 2013). This association emphasizes just how heavily pursuing societally defined happiness can impact psychological health - happiness can be lost and found in crooked front teeth. 


\section{Conclusion}

The pursuit of happiness certainly does not have the monopoly over the causes of human psychological stress. There are many other sources of anguish and anxiety, however only a few have the capacity to inflict chronic stress over a lifetime. Distinct groups of people tend to shoulder specific persistent stressors; these could include humans in disadvantaged parts of the world or those who contend with religious and racial discrimination. The pursuit of happiness, however, is not selective; it is a ubiquitous endeavor familiar to all and its realization does not necessarily favor the poor or the rich. The idea that the pursuit of happiness can be self-defeating is not new; it has been scattered through philosophical discussion for millennia. In saying this, modern day scientific research on happiness is still in a nascent stage. Many research methods measure incorrect indicators of happiness, often focusing on macroeconomics and/or microeconomics. Appropriate scientific exploration will help to promote a wider understanding, more beneficial perspectives and less distressful interpretations of this multifaceted societal ideal. If happiness and its pursuit can result in a lifetime or even lengthy bouts of low-level stress, it deserves broad and creative objective attention.

\section{References}

Alam, M., Barrett, K. C., Hodapp, R. M., \& Arndt, K. A. (2008). Botulinum toxin and the facial feedback hypothesis: Can looking better make you feel happier? Journal of the American Academy of Dermatology, 58(6), 1061-1072.

Andres, L., Adamuti-Trache, M., Yoon, E.-S., Pidgeon, M., \& Thomsen, J. P. (2007). Educational expectations, parental social class, gender, and postsecondary attainment: A 10-year perspective. Youth \& Society, 39(2), 135163.

Argyle, M. (1997). Causes and correlates of happiness. In D. Kahneman, E. Diener \& N. Schwartz (Eds.), Undestanding well-being: Scientific perspectives on enjoyment and suffering (pp. 353-373). New York: Russell Sage.

Aristotle, \& Jackson, H. (1973). The fifth book of the Nicomachean ethics of Aristotle. New York: Arno Press.

Baum, A., Garofalo, J. P., \& Yali, A. M. (1999). Socioeconomic status and chronic stress: Does stress account for SES effects on health? Annals of the New York Academy of Sciences, 896, 131-144.

Bayar, G. R., Tutuncu, R., \& Acikel, C. (2012). Psychopathological profile of patients with different forms of bruxism. Clinical Oral Investigations, 16(1), 305-311.

Benoliel, R., Svensson, P., Heir, G. M., Sirois, D., Zakrzewska, J., Oke-Nwosu, J., Torres, S. R., Greenberg, M. S., Klasser, G. D., Katz, J., \& Eliav, E. (2011). Persistent orofacial muscle pain. Oral Diseases, 17(Supplement s1), 23-41.

Berkman, L. F., \& Syme, S. L. (1979). Social networks, host resistance, and mortality: A nine-year follow-up study of Alameda county residents. American Journal of Epidemiology, 109(2), 186-204.

Bradbury, E. (1994). The psychology of aesthetic plastic surgery. Aesthetic Plastic Surgery, 18(3), 301-305. 
Brickman, P., Coates, D., \& Janoff-Bulman, R. (1978). Lottery winners and accident victims: Is happiness relative? Journal of Personality and Social Psychology, 36(8), 917-927.

Burchardt, T. (2005). Are one man's rags another man's riches?: Identifying adaptive expectations using panel data. Social Indicators Research, 74(1), 57-102.

Cannon, W. B. (1914). The emergency function of the adrenal medulla in pain and the major emotions. American Journal of Physiology, 33(2), 365-372.

Clark, A. E., Frijters, P., \& Shields, M. A. (2008). Relative income, happiness, utility: An explanation for the Easterlin paradox and other puzzles. Journal of Economic Literature, 46(1), 95-144.

Cole, S. (2012). Social regulation of gene expression in the immune system. In S. Segerstrom (Ed.), The Oxford handbook of psychoneuroimmunology (pp. 254-273). New York: Oxford University Press.

Darwin, C. (1965). The expression of the emotions in man and animals. Chicago: University of Chicago Press.

Davis, J. I., Senghas, A., \& Ochsner, K. N. (2009). How does facial feedback modulate emotional experience? Journal of Research in Personality, 43(5), 822-829.

Deci, E. L., Koestner, R., \& Ryan, R. M. (1999). A meta-analytic review of experiments examining the effects of extrinsic rewards on intrinsic motivation. Psychological Bulletin, 125(6), 627-668.

Derogatis, L. R., \& Unger, R. (2010). Symptom checklist-90-revised. In I. B. Weiner \& W. E. Craighead (Eds.), The Corsini Encyclopedia of Psychology (Vol. 4, pp. 1743-1744). Hoboken, NJ: John Wiley \& Sons, Inc.

Diemer, M. A., \& Hsieh, C.-a. (2008). Sociopolitical development and vocational expectations among lower socioeconomic status adolescents of color. Career Development Quarterly, 56(3), 257-267.

Durham, J. (2008). Temporomandibular disorders (TMD): An overview. Oral Surgery, 1(2), 60-68.

Dworkin, S. F., \& Burgess, J. A. (1987). Orofacial pain of psychogenic origin: Current concepts and classification. The Journal of the American Dental Association, 115(4), 565-571.

Dworkin, S. F., \& LeResche, L. (1992). Research diagnostic criteria for temporomandibular disorders: Review, criteria, examinations and specifications, critique. Journal of Craniomandibular Disorders, 6(4), 301-355.

Easterlin, R. A. (1974). Does economic growth improve the human lot? Some empirical evidence. In P. A. David \& M. W. Reder (Eds.), Nations and households in economic growth: Essays in honor of Moses Abramovitz (pp. 89125). New York: Academic Press, Inc.

Easterlin, R. A. (2003). Explaining happiness. PNAS (Proceedings of the National Academy of Sciences), 100(19), 11176-11183.

Feng, X. P., Newton, J. T., \& Robinson, P. G. (2001). The impact of dental appearance on perceptions of personal characteristics among Chinese people in the United Kingdom. International Dental Journal, 51(4), 282-286.

Finch, C. E. (2007). The biology of human longevity: Inflammation, nutrition, and aging in the evolution of lifespans. Burlington, MA: Academic Press.

Fontane, P. E. (1996). Exercise, fitness, and feeling well. American Behavioral Scientist, 39, 288-305.

Frank, R. H. (1997). The frame of reference as a public good. The Economic Journal 107(445), 1832-1847. 
Fredrickson, B. L., Grewen, K. M., Coffey, K. A., Algoe, S. B., Firestine, A. M., Arevalo, J. M. G., Ma, J., \& Cole, S. W. (2013). A functional genomic perspective on human well-being. Proceedings of the National Academy of Science of the United States of America, 110(33), 13684-13679.

Freedman, J. L. (1978). Happy people: What happiness is, who has it, and why. New York: Harcourt.

Frey, B. S. (2008). Happiness: A revolution in economics. Cambridge, Mass.; London: MIT Press.

Frey, B. S., \& Stutzer, A. (2002). Happiness and economics: How the economy and institutions affect well-being. Princeton, NJ: Princeton University Press.

Friedman, E. M. (2012). Well-being, aging, and immunity. In S. Segerstrom (Ed.), The Oxford handbook of psychoneuroimmunology (pp. 37-62). New York: Oxford University Press.

Fromm, E. (2009). To have or to be? London; New York: Continuum

Galati, D., Manzano, M., \& Sotgiu, I. (2006). The subjective components of happiness and their attainment: A crosscultural comparison between Italy and Cuba. Social Science Information, 45(4), 601-630.

Geers, A. L., \& Lassiter, D. D. (1999). Affective expectations and information gain: Evidence for assimilation and contrast effects in affective experience. Journal of Experimental Social Psychology, 35(4), 394-413.

Gerwin, R. D. (2001). Classification, epidemiology, and natural history of myofascial pain syndrome. Current Pain and Headache Reports, 5(5), 412-420.

Gungormus, Z., \& Erciyas, K. (2009). Evaluation of the relationship between anxiety and depression and bruxism. Journal of International Medical Research, 37(2), 547-550.

Helliwell, J., Layard, R., \& Sachs, J. (2013). World happiness report 2013 (pp. 1-154). New York: The United Nations Sustainable Development Solutions Network (UNSDSN).

Helliwell, J. F., \& Putnam, R. D. (2004). The social context of well-being. Philosophical Transactions - Royal Society of London Series B Biological Sciences, 359, 1435-1446.

Hidaka, O., Yanagi, M., \& Takada, K. (2004a). Changes in masseteric hemodynamics time-related to mental stress. Journal of Dental Research 83(2), 185-190.

Hidaka, O., Yanagi, M., \& Takada, K. (2004b). Mental stress-induced physiological changes in the human masseter muscle. Journal of Dental Research, 83(3), 227-231.

Inglehart, R., \& Rabier, J.-R. (1986). Aspirations adapt to situations - But why are the Belgians so much happier than the French? A cross-cultural analysis of the subjective quality of life. In F. M. Andrews (Ed.), Research on the quality of life (pp. 1-56). Ann Arbor, MI: University of Michigan.

Irwin, M. R., \& Cole, S. W. (2011). Reciprocal regulation of the neural and innate immune system. Nature Reviews Immunology, 11(9), 625-632.

Jamieson, J. P., Mendes, W. B., \& Nock, M. K. (2013). Improving acute stress responses: The power of reappraisal. Current Directions in Psychological Science 22(1), 51-56.

Johnston, C., Hunt, O., Burden, D., Stevenson, M., \& Hepper, P. (2010). Self-perception of dentofacial attractiveness among patients requiring orthognathic surgery. The Angle Orthodontist, 80(2), 361-366. 
Jung, J., Lennon, S. J., \& Rudd, N. A. (2001). Self-schema or self-discrepancy?: Which best explains body image? Clothing and Textiles Research Journal, 19(4), 171-184.

Kinnunen, T. (2010). A second youth: Pursuing happiness and respectability through cosmetic surgery in Finland. Sociology of Health \& Illness, 32(2), 258-271.

Klages, U., \& Zentner, A. (2007). Dentofacial aesthetics and quality of life. Seminars in Orthodontics, 13(2), 104115 .

Komiyama, O., Wang, K., Svensson, P., Arendt-Nielsen, L., Kawara, M., \& Laat, A. D. (2009). Ethnic differences regarding sensory, pain, and reflex responses in the trigeminal region. Clinical Neurophysiology, 120(2), 384-389.

Kraft, T. L., \& Pressman, S. D. (2012). Grin and bear it: The influence of manipulated facial expression on the stress response. Psychological Science, 23(11), 1372-1378.

Lane, R. E. (2000). The loss of happiness in market democracies. New Haven and London: Yale University Press.

LeResche, L., Manci, L. A., Drangsholt, M. T., Huang, G., \& Von Korff, M. (2007). Predictors of onset of facial pain and temporomandibular disorders in early adolescence. Pain, 129(3), 269-278.

Lu, L., Gilmour, R., \& Kao, S. F. (2001). Cultural values and happiness: An East-West dialogue. The Journal of Social Psychology, 141(4), 477-493.

Lykken, D., \& Tellegen, A. (1996). Happiness is a stochastic phenomenon. Psychological Science, 7(3), $186-189$.

Manfredini, D., \& Lobbezoo, F. (2009). Role of psychosocial factors in the etiology of bruxism. Journal of Orofacial Pain, 23(2), 153-166.

Maslow, A. H. (1943). A theory of human motivation. Psychological Review, 50(4), 370-396.

Mauss, I. B., Tamir, M., Anderson, C. L., \& Savino, N. S. (2011). Can seeking happiness make people unhappy? Paradoxical effects of valuing happiness. Emotion, 11(4), 807-815.

McMahon, D. M. (2006). Happiness: A history. New York: Atlantic Monthly Press.

McNeill, C., Mohl, N. D., Rugh, J. D., \& Tanaka, T. T. (1990). Temporomandibular disorders: Diagnosis, management, education and research. The Journal of the American Dental Association, 120(3), 253-257.

Mercuri, L. (2013). A heuristic approach to the management of muscle-related temporomandibular disorders. Faculty Dental Journal, 4(3), 112-117.

Myers, D. G., \& Diener, E. (1995). Who is happy? Psychological Science, 6(10-19).

New Economics Foundation. (2012). Happy planet index 2012 (Online Data). Available from Global Finance, from New Economics Foundation http://www.gfmag.com/tools/global-database/ne-data/11940-happiestcountries.html\#axzz2b28t7AX7

Okeson, J. P. (1996). Orofacial pain: Guidelines for assessment, diagnosis, and management. Hanover Park, IL: Quintessence Publishing Company.

Pabari, S., Moles, D. R., \& Cunningham, S. J. (2011). Assessment of motivation and psychological characteristics of adult orthodontic patients. American Journal of Orthodontics and Dentofacial Orthopedics, 140(6), $263-272$.

Palmer, L. K. (1995). Effects of a walking program on attributional style, depression, and self-esteem in women. Perceptional and Motor Skills, 81, 891-898. 
Passatore, M., \& Roatta, S. (2007). Modulation operated by the sympathetic nervous system on jaw reflexes and masticatory movement. Archives of Oral Biology, 52(4), 343-346.

Pithon, M. M., Andrade, D., Fernandes, I., Mendes, J., Nunes, K., Michele, L., Ribeiro, A. V., \& da Silva Coqueiro, R. (2013). Influence of malocclusion on social perceptions of adolescents at public and private schools. European Archives of Paediatric Dentistry, 1-7.

Plante, T. G., \& Rodin, J. (1990). Physical fitness and enhanced psychological health. Current Psychology, 9(1), 324.

Plesh, O., Crawford, P. B., \& Gansky, S. A. (2002). Chronic pain in a biracial population of young women. Pain, 99(3), 515-523.

Prabakaran, R., Seymour, S., Moles, D. R., \& Cunningham, S. J. (2012). Motivation for orthodontic treatment investigated with Q-methodology: Patients' and parents' perspectives. American Journal of Orthodontics and Dentofacial Orthopedics, 142(2), 213-220.

Radley, J. J. (2012). Toward a limbic cortical inhibitory network: Implications for hypothalamic-pituitary-adrenal responses following chronic stress. Frontiers in Behavioral Neuroscience, 6, 1-10.

Ryan, R. M., \& Deci, E. L. (2001). On happiness and human potentials: A review of research on hedonic and eudaimonic well-being. Annual Review of Psychology, 52(1), 141-166.

Ryff, C. D., \& Singer, B. H. (1996). Psychological well-being: Meaning, measurement, and implications for psychotherapy research. Psychother Psychosom, 65(1), 14-23.

Ryff, C. D., Singer, B. H., \& Love, G. D. (2004). Positive health: Connecting well-being with biology. Philosophical Transactions-Royal Society of London Series B Biological Sciences, 1383-1394.

Schooler, J. W., Ariely, D., \& Loewenstein, G. (2003). The pursuit and assessment of happiness may be selfdefeating. In J. Carrillo \& I. Brocas (Eds.), The psychology of economic decision (pp. 41-70). Oxford: Oxford University Press.

Schooler, J. W., \& Mauss, I. B. (2010). To be happy and to know it: The experience and meta-awareness of pleasure. In M. L. Kringelbach \& K. C. Berridge (Eds.), Pleasure of the brain (pp. 244-254). New York: Oxford University Press.

Selye, H. (1975). Confusion and controversy in the stress field. Journal of Human Stress, 1(2), 37-44.

Selye, H. (1976). Forty years of stress research: Principal remaining problems and misconceptions. Canadian Medical Association Journal, 115(1), 53-56.

Sheldon, K. M., \& Lyubomirsky, S. (2006). Achieving sustainable gains in happiness: Change your actions, not your circumstances. Journal of Happiness Studies, 7(1), 55-86.

Simons, D. G., Travell, J. G., \& Simons, L. S. (1999). Mysofascial pain and dysfunction: The trigger point manual (2 ed. Vol. 1). Baltimore: Lippincott Williams \& Wilkins.

Solnick, S. J., \& Hemenway, D. (1998). Is more always better?: A survey on positional concerns. Journal of Economic Behavior and Organization, 37(3), 373-383.

Steele, L. G., \& Lynch, S. M. (2012). The pursuit of happiness in China: Individualism, collectivism, and subjective well-being during China's economic and social transformation. Social Indicators Research, 1-11. 
Suvinen, T. I., Reade, P. C., Kemppainen, P., Könönen, M., \& Dworkin, S. F. (2005). Review of aetiological concepts of temporomandibular pain disorders: Towards a biopsychosocial model for integration of physical disorder factors with psychological and psychosocial illness impact factors. European Journal of Pain, 9(6), 613633.

Tkach, C., \& Lyubomirsky, S. (2006). How do people pursue happiness?: Relating personality, happiness-increasing strategies, and well-being. Journal of Happiness Studies, 7(2), 183-225.

Uchida, Y., Norasakkunkit, V., \& Kitayama, S. (2004). Cultural constructions of happiness: Theory and empirical evidence. Journal of Happiness Studies, 5(3), 223-239.

Velly, A. M., Look, J. O., Schiffman, E., Lenton, P. A., Kang, W., Messner, R. P., Holcroft, C. A., \& Fricton, J. R. (2010). The effect of fibromyalgia and widespread pain on the clinically significant temporomandibular muscle and joint pain disorders -- A prospective 18-month cohort study. The Journal of Pain, 11(11), 1150-1164.

Verdecchia, F., Bee, M., Lombardo, L., Sgarbanti, C., \& Gracco, A. (2011). Influence of anterior tooth alignment on peer perception in 8- to 10-year-old children. The European Journal of Orthodontics, 33(2), 155-160.

Waterman, A. S. (1993). Two conceptions of happiness: Contrasts of personal expressiveness (eudaimonia) and hedonic enjoyment. Journal of Personality and Social Psychology, 64(4), 678-691.

Wegner, D. M. (1994). Ironic processes of mental control. Psychological Review, 101(1), 34-52.

Zizzo, D. J., \& Oswald, A. (2001). Are people willing to pay to reduce others' incomes? Annales d'Economie et de Statistique, (63-64), 39-65. 